\title{
Lipman, Dewey, and Philosophical Inquiry in the Mathematics Classroom
}

\section{Nadia Stoyanova Kennedy}

\section{Abstract}

The paper discusses Matthew Lipman's approach to inquiry as shaped and fashioned by John Dewey's model of scientific inquiry. Although Lipman's program adopted the major aspects of Dewey's pedagogy, at least two characteristics of that program stand out as radically different-his use of relatively free-form philosophical discussions to teach complex thinking, and his formulation and development of what he called a "community of inquiry" as a pedagogical setting for holding and sustaining such discussions. Here Lipman's Philosophy for Children program is seen as a framework for the design and performance of philosophical inquiry in the disciplines-something that he himself contemplated but never realized. In this paper I outline a few possible directions for opening spaces in school-based mathematical practices for philosophical deliberation in a community of inquiry, Lipman style. I argue that such an opening represents a potential expansion of students' mathematical experiences - a way of nurturing and integrating a sense of the philosophical perspectives of the discipline into the regular math class that is larger and more encompassing, and that promises to provide bridges for establishing richer and more meaningful connections and interactions with students' personal experience, with other disciplines, and with the broader culture; and thus a prime example of what Dewey called "educative experience." 


\section{Introduction}

One of John Dewey's major contributions to the reconstruction of the educational process was in his understanding that education needed to develop a working relationship between the refined end-products of inquiry that are codified and sedimented in textbooks, and the raw subject matter inquiry that is natural to the young. Such inquiry, he was convinced, should be shaped and fashioned to the well-known model of scientific inquiry which he set forth in How We Think (Dewey, 1933). In that same book, he describes "reflective thinking" as a special kind of ratiocination that is aware of its means and consequences, and thus is a major instrument in discipline-based inquiry. Dewey's "scientific method" became a blueprint for the various critical thinking programs that emerged in the US in the 1970s, and a formative influence on Matthew Lipman's Philosophy for Children program, which was also developed during that decade.

Although Lipman's program adopted the major aspects of Dewey's pedagogy, at least two characteristics of the program stand out as radically different-his use of relatively free-form philosophical discussions to teach complex thinking, and his formulation and development of what he called a "community of inquiry" (CI) as a pedagogical setting for holding and sustaining such discussions. As Lipman notes, Dewey never took up the question of the educational use of philosophy in the classroom, nor did he conceive of his model of scientific inquiry as of particular use for classroom philosophical inquiry (Lipman, 2003). On the other hand, Lipman seems to have seen philosophical inquiry as a more promising way to formulate an inquiry-based educational model than the scientific method. He wrote, "I saw philosophy as the discipline par excellence for making sense of things and for preparing students to think in the more specific disciplines" (Lipman, 1996, p. xv).

Lipman's community of philosophical inquiry is in fact a creative compilation of C.S. Peirce's (1931/32) community of scientific inquirers, Josiah Royce's (1968) community of interpretation, which takes on Dewey's (1933) notion of scientific inquiry as originating in everyday problem solving, and G. H. Mead's (1934) notion of the genesis of the community through communication and of the "thinking self" through internalizing that communication. As just noted, Dewey's idea for the reconstruction of education follows the lines of scientific inquiry, and Lipman's is focused on the philosophical. The fact that reflective thinking operates in both the scientific and the philosophical community of inquiry makes it operationally possible to conceive of a discipline-based inquiry practice that combines both dimensions, and to envision them as shifting between the one and the other. Both dimensions can complement each other, in that the scientific or mathematical can provide grounding and material for more general philosophical thinking, and the philosophical can help to analyze and clarify the meanings of scientific concepts, explore the assumptions of the discipline, and investigate what a mathematical or scientific description can and cannot tell us about the reality it describes, as well as what the implications of the uses of science and mathematics in society are or 
might be. Thus each type of inquiry can add extra depth to the other, and also help us increase our awareness of what each can and cannot accomplish.

It is of particular significance for this discussion that Lipman's Philosophy for Children program represents a living model that can be used as a framework for the design and performance of philosophical inquiry in all disciplines-something that he himself contemplated but never realized. In this short paper, I will outline a few possible directions for opening spaces in school-based mathematical practices for philosophical deliberation in a community of inquiry, Lipman style. I will argue that such an opening represents a potential expansion of students' mathematical experiences - a way of nurturing and integrating a sense of the philosophical perspectives of the discipline into the regular math class that is larger and more encompassing, and that promises to provide bridges for establishing richer and more meaningful connections and interactions with students' personal experience, with other disciplines, and with the broader culture. But before embarking on this task, I will briefly delineate some key points of Lipman's approach that are extrapolated from Dewey's educational thought, and which I consider essential for this discussion of the possibilities for and implications of conducting philosophical inquiry in the mathematics classroom.

\section{Key Points in Lipman's Approach to Philosophical Inquiry}

In his Philosophy for Children program, Lipman adopts virtually all the major elements of Dewey's pedagogy, including his emphasis on the primacy of thinking in education, and on the formation of habits of reflective thought as an ongoing process of reconstruction. In How We Think, Dewey succinctly describes the major tenets of such habit formation: "the problem of method in forming habits of reflective thought is the problem of establishing conditions that will arouse and guide curiosity; of setting up the connections in things experienced that will on later occasions promote the flow of suggestions, create problems and purposes that will favor consecutiveness in the succession of ideas" (LW 8: 157).

Lipman took from Dewey the notion that inquiry should begin with a particular experience-in this case a reading from a specially prepared philosophical novel, an exercise, or a list of questions - in order to provoke a unified cognitive event that is impregnated with conflicting ideas, that can prompt students to encounter uncertainty and perplexity, and that motivates them to inquire into the problematic of a situation and to search for its resolution. The communal deliberative discussions that are the hallmark of Lipman's method are natural outgrowths of previous discussions, intelligently guided by the teacher-facilitator, who as Lipman (1980) puts it, is always attempting to find the balance between "taking concepts apart and putting them back together" and between "generalizing and particularizing," and whose goal is to move the discussion onto a "higher level of generality." The communal thinking process that results is reminiscent of Vasily Davydov's prescriptive outline for theoretical thinking as a process that aims at grasping the 
general structural principles of a given learning situation and then locating those general patterns in basic, concrete problems (Davydov, 1990).

The agenda of the Lipmanian group discussion is guided by students' interests, not by the logical organization of the subject matter. The latter is something that Dewey (1933) insisted was paramount for acquiring intrinsic meaning and understanding, but Lipman insists on the primacy of the students' questions, induced by the problematic of a presented stimulus that guides the agenda of inquiry, and his goal is that students' questions and interventions guide the inquiry process itself. In this case, what is seen and felt as problematic and perplexing in the situation presented by the stimulus must reflect the experiences of the group of students, or as Dewey puts it, the situation must "occasion" the inquiry.

Philosophical inquiry, in Lipman's usage, is an encompassing term that signifies work related to reasoning and making judgments, conceptual analysis, and engagement in interpersonal communication and deliberation. His community of inquirers is understood as a habitat that facilitates the development of higher order thinking, and which operates, as Vygotsky would have it, in a collective zone of proximal development that is more advanced than any individual member of the collective (Vygotsky, 1978). Meaning construction is embedded in a process of concept reconstruction, and carried forward by collective and collaborative argumentation-a coconstructed process whereby propositions are made and justifications required, examined, agreed with, or contested. Disagreement forces deeper work on what warrants the given justifications, and it drives the group to develop and evaluate criteria for the making of judgments. As the given problematic is reflected upon by the group, the discussion moves from assimilation of frames and references, to reflection on the definition of terms, to exploring means for resolving the contradictions and aporias that have emerged, and finally to the conscious attempt at a productive judgment or set of judgments.

The community of inquiry, by virtue of being the common space where interpersonal meanings are coconstructed and negotiated, and a matrix in which what has been internalized by individuals gets externalized in new communication, also produces individual dispositions and reflective habits that are internalizations of procedures that originate in the community. As such, the experience of communal philosophical inquiry, when it functions optimally, is an exemplar of what Dewey called "educative experience." Such experience is affectively engaging and intelligently directed, where habit is challenged by impulse, impulse is disciplined by habit, and real interest results in creative communication, thereby propelling expression of each individual's powers through action. As Lipman simply put it, "Where meaning accrues there is education" (1980, p. 27).

The ideal communal inquiry experience is thus potentially transformative, and the transformation in question is that of subjectivity itself. Through the process of critical reflection on the problematic aspects of thought, language, and experience, members learn to isolate, combine, and recombine elements of their 
own experience, thereby reconstructing it. It exemplifies Dewey's notion of the transactional, whereby a situation comes to embody "complete interpenetration of self and the world of objects and events" (LW 10:25). The reconstruction of habit that ensues is marked by a broadened perspective, a shift of attitude, an increase in knowledge-in short, in enduring changes of a psychological nature that follow from the acquisition of new meanings. And on a social level, community of philosophical inquiry opens spaces for collective participation in the deliberative processes of appreciation, discernment, evaluation, of judging rather than passing judgment, opening discursive space for reasonable doubting, for not taking things for granted, for questioning assumptions - all aspects of what might be called "the philosophical attitude."

Through dialogical philosophical inquiry, Lipman sought to pursue what Dewey called "intellectual education" - the transformation of students' raw powers into more refined, intelligent habits that engender deliberate, disciplined, and thorough inquiry when a situation calls for it. His ambition was to organize an environment for educative experience that supports the expansion of students' habits of engagement, as well as a stable and sustained desire for further learning. Lipman was very much aware of the possibility that increased sensitivity, reasoned judgment, and consciously maintained habits of thought can serve not only to accelerate children's intellectual and psychological growth, but also to enlarge their desire for further learning and their capacity for growth. For that to happen, the intelligent organization of communal inquiry must guide those raw powers so as to generate a mutually reinforcing matrix in which students' individual powers support each other well beyond what can develop in isolation.

\section{Wonder: The Lost Dimension in Mathematics Classroom Practice}

Dewey's question as to why "children are so full of questions outside of school (so they pester grown-up persons if they get any encouragement)," yet somehow demonstrate a "conspicuous absence of display of curiosity about subject matter of school lessons" is still pertinent today, and especially so when we speak about math lessons (1916, p. 155). Apart from the regular display of student apathy in the math classroom, school mathematical practices are notorious for producing math phobias and negative attitudes among a significant number of students (see, e.g., Tobias, 1993). A survey cited in Hersh and John-Steiner's recent book, Loving and Hating Mathematics (2011), indicates that $40 \%$ of the adults interviewed reported aversive reactions to mathematics in school. The fact that students begin to dislike mathematics in their middle school years, usually between $4^{\text {th }}$ and $8^{\text {th }}$ grades, suggests that at some point the experience of mathematics turns "mis-educative" (Middleton \& Spanias, 1999; House, 2006). Research into this phenomenon proposes that it is a result of the ignoring of students' interests, a pedagogy based on routine, the dominance of trivial activities and tasks, the increasing disconnection 
of the subject matter from students' everyday knowledge and experience, and the perceived irrelevance of math to students' lives (see, e.g., Wells, 1999; Boaler, 2002). As a result, the driving force of learning-curiosity—is lost.

It is relevant here that Dewey ultimately refines his notion of curiosity in making a distinction between children's general inquisitiveness, playful manipulation, and information seeking and what he terms "intellectual curiosity." Paolo Freire in fact makes the same distinction between what he calls "ingenuous" and "epistemological" curiosity, identifying the latter as an interest not just in what one knows but also in how one knows it. On both accounts, students' natural curiosity requires stimulation and nurturance in order to develop in the direction of ongoing inquiry, not just about the world and their place in it, but additionally in the powers and limits of their own thinking. In this vein, Lipman (1996) suggests that in inaugurating a community of inquiry in the classroom, the teacher should provide a space-he calls it a "buffer"-between the culture and the child, where the child, together with others in a structured and disciplined inquiry environment, can make meaning and sense of the relation between the material and the social world, on the one hand, and the world of ideas that she encounters in the classroom, on the other.

Community of inquiry is not a new idea in mathematics education. The constructivist approach shared by leading math educators (e.g., Schoenfeld, 1989; Lampert, 1990; Cobb, Wood \& Yackel, 1991; Cobb Boufi, McClain, \& Whitenack, 1997; Boaler \& Humphreys, 2005; Goos, 2004) has long encouraged the creation of learning environments that recognize and utilize students' informal knowledge and spontaneous concept development, and that leads students to work primarily in collaboration with their peers on mathematical tasks that are designed to encourage individual and group inquiry, the communication of mathematical ideas, and the communal exploration of proposed conjectures. Various forms of group processes called "community of inquiry" have been consistently explored by teachers, researchers, and other practitioners in math education for the last 30 years, and a few have been hailed as a major pedagogical innovation in the discipline (NCTM, 2000). However, while all of these forms of CI-whether called community of inquiry, community of learners, or community of practice-have been successful in promoting an exploration approach to mathematics, the exploration in question has typically remained in the traditional context of mathematical problem solving. In other words, the CI model has been exclusively focused on mathematical inquiry and other mathematical practices strictly circumscribed by disciplinary boundaries. Introducing Lipman's broader philosophical approach to inquiry within the discipline promises a more integral connection and communication between past and current experiences in mathematics by empowering students to draw more extensively on previous knowledge, to think in more complex terms about the world, and to begin to overcome those yawning epistemological gaps between mathematical practices and the world of everyday reasoning and perception. 


\section{Opening Spaces for Philosophical Inquiry in Mathematics Classroom Practices}

The notion of "opening" a philosophical space in the mathematics classroom is of necessity imprecise and even misleading, given that this space is already a part of the epistemological terrain of any discipline, mathematics included. In current practice, it is a dormant or occulted space, a space ignored or concealed by mechanical pedagogies, and considered irrelevant to the acquisition of mathematical knowledge per se. I would suggest that the irrelevancy argument will not stand close scrutiny, however, given that philosophical inquiry is ultimately about concepts, and that any inquiry into mathematical concepts should facilitate and expand student understanding. This is doubly obvious if we recognize mathematics not as a monolithic system, but as a human conceptual construction, and view mathematical objects as embodied concepts (Lakoff \& Nunez, 2000). Mathematical concepts are constructs grounded in experience, and they can be encountered in different forms and under different aspects-never as a totality, but more as an assemblage of different elements that manifest themselves in different contexts (Deleuze \& Guattari, 1994).

Any individual's concepts are grounded in his or her lived experience, and their growth is shaped to a great extent by personal belief and personalized processes of verification. Thus it is to be expected that there will be differences in the relationships between each student's naïve and scientific concepts, between each student's ability to navigate between descriptive and normative thinking, and in each student's capacity to "break set" and think analogically, metaphorically, and across conventional categories. In an environment of communal, dialogical deliberation, these differences tend to emerge spontaneously in the course of discussions connected to a particular concept, and if the teacher allows and even encourages their expressions, mathematical inquiry often merges seamlessly into philosophical inquiry. For example, on one occasion I was working with a group of middle school students in comparing the infinite set of all natural numbers to the infinite set of even natural numbers, in order to answer the question whether those sets have equal numbers of elements. As the group struggled to work through several conflicting hypotheses, one student asked, "Is infinity a number?" I seized the moment, and reoriented the mathematical inquiry towards a philosophical one by paraphrasing the question as "What is infinity?" The following discussion ensued:

Jimmy: Infinity is not a number.

Chas: Infinity is not a number, a . . it's just in there ...

Sally: If numbers are going forever I guess it's a number.

Chas: It's not exactly a number, that's the name of the rest of the numbers, ... and they might skip a number when they go through, they might go odd, odd, even, even, odd, even. It's a problem that they can change. 
Rush: $\quad$. . because the number infinity, it's not like 1000 billion, or 1000 trillion, it's not like that and there is a whole bunch of numbers inside infinity, so we don't know whether inside they're skipping odd, even, even, even, odd.

Claire: And what number comes before infinity? I don't really think that infinity is a number. Or a bunch of numbers, what Rush is saying.

Sally: He said that all the numbers are packed inside.

Jimmy: I think infinity is not a number, we just say this wayendless.

Chas: $\quad$ That's what we said.

Mark: $\quad$ Everybody seems to be saying this.

Victor: We are making our own definitions, 'cause the dictionary is written by people and I think they may not be always right. Infinity is just numbers that are too big.

Jimmy: Infinity just means expanding and expanding and expand ing. It means infiniteness.

Sally: $\quad$ O.K. That means that there are no numbers packed in in finity, but we just have infinite numbers packed in these sets [in the infinite sets].

What, then, was learned here? The sudden shift in discourse created a space for students to agree and to disagree, to take apart and reassemble the concept of infinity even as they reflected on their own experiences and evaluated the propositions put forth by their peers. Apart from the reconstruction of concepts, this process also included the realization that different individuals conceive of infinity differently, but also that it is possible to hold back, to suspend one's spontaneous judgments in order to refine the process of discernment, and that there is a sort of natural, intuitive methodology available to everyone for evaluating different conceptual positions. These discursive shifts from concrete mathematical inquiry to philosophical inquiry and back to the mathematical promise to help students make sense of their previous experiences in the situation defined by the current problematic, to enrich meaning, and to enlarge conceptual understanding. Not always, however, will there be such spontaneous emergence of a space in which mathematical and philosophical inquiry can interact and, so to speak, cross-pollinate. A framework is needed for a more permanent space, an "in-between" where the two conceptual universes can interact regularly.

Such an in-between space is available as part of a broader curricular framework that places philosophy and all the disciplines in a situation of encounter. A major pedagogical avenue for philosophical inquiry, and one demanding more work on the part of the teacher than is traditionally expected, is the method of problematizing the common, central, and contestable concepts that are shared by the disciplines of the school curricula-concepts like measurement, fact, objectivity, 
certainty, change, chance, equality, structure, and so on. Each of these concepts is an assemblage of different meaning aspects derived from the disciplinary landscape it populates. For example, measuring an object's height in mathematics or physics is different from measuring learning, or anxiety, or the difference between two poems. Examination of the meanings of the same concept across different knowledge domains can allow new aspects of the former to be brought to light. It may produce a new synthesis of the problematized concept, as well as a heightened awareness and sophistication in its application to mathematical or empirical tasks. Indeed, since every concept is related to other concepts, it is impossible to approach a thorough grasp of a concept without tracing its connections with others, and without examining the latter in the process of, in Deleuze and Guattari's (1994) words, "bringing forth" its meaning. This form of problematization can be seen in Dewey's notion of "psychologizing" the subject matter, and presenting it in such a way that it becomes an occasion for philosophical inquiry. Lipman's method involves problematizing the concept by pushing it beyond "normal" semantic boundaries into "fuzzy" areas, and highlighting aspects of it and its connections with other concepts that customarily are not part of our conscious or unconscious associations and beliefs, and, as such, interrupting our mundane and trivial use of the concept. This is suggestive of Deleuze's notions of deterritorialization and reterritorialization-like, in their somewhat extreme vocabulary, "hurling" the concept from its natural domain and "sending" it off to a territory in which it doesn't belong in order to "turn it back against itself so as to summon forth a new earth" (Deleuze \& Guattari, p. 99).

For example, in problematizing the concept "algorithm," which might be defined as "a finite sequence of well-defined instructions for completing a task," we might examine the differences between the use of the concept in our everyday lives and its use in mathematics. One may inquire whether "algorithm" is recognizable in psychological and sociological contexts-do we think algorithmically in our everyday activities? Are there subconscious or unconscious algorithms that guide or underlie events like arguments, or shopping expeditions? Is an unconscious algorithm an algorithm at all, or something else? Is there a difference between algorithms for assembling a device of some kind and algorithms in mathematics? Is a mathematical formula an algorithm? Does the use of any algorithm require mathematical reasoning, and if so, what kind of reasoning? These questions interrogate the relation between this concept and other related concepts, such as "automatization," and even thinking in general. Making distinctions between concepts, and mapping a whole neighborhood of concepts that are seemingly close in meaning, is part of this sort of conceptual work, and as in the example above, concepts like algorithm, method, formula, plan, strategy, routine, and others can be reflected upon, clarified, and enriched in this way. Our expectation is that, after exporting the concept into other contexts and examining it there, our understanding is enhanced when it is re-imported into the universe of mathematics, with all of its newly acquired dimensions accrued from its traversal of other disciplines. Similarly, spaces 
for the problematization of more strictly mathematical concepts may be located among the discrepancies between different students' definitions, interpretations, and understandings of a given concept, in the exploration of the relations between various internal aspects of a concept, or the relationships between it and other related concepts (Kennedy, 2012a; Kennedy, 2012b; Kennedy \& Kennedy, 2011). This can be understood as a kind of conceptual boundary work, which acts not only to reveal and explore any ambiguity, vagueness, and misunderstanding in our understanding of the concept and its use, but also to reconstruct our conceptual schemata through a process of deterritorialization and reterritorialization.

\section{Mathematization, Citizenship, and the Reconstruction of Habit}

Beyond the conceptual work outlined above, philosophical inquiry can also serve to furnish a more global perspective regarding mathematics, its nature, its aesthetic and ethical dimensions, and the cultural and political implications of the uses of mathematics in our society. To include opportunities in the curriculum for aesthetic inquiry into mathematical concepts through exploring phenomena like symmetry, fractals, patterns, and more offers the possibility of expanding student powers towards not only the appreciation of mathematical beauty, but also of developing criteria for aesthetic judgment in general. Inquiries into questions such as "Is there a connection between symmetry and beauty?" "When is a pattern beautiful?" "What is an elegant math solution or proof?" and others not only may prompt students to think about math concepts in new ways, but also offers them the freedom of opportunity to relate to mathematics itself in a new way, and to have new experiences of "relatedness" that go beyond the current utilitarian concerns of the curriculum and its characteristic texts.

For example, a major portion of the current school mathematics curriculum is devoted to utilizing or developing mathematical models that represent and can usefully describe a situation, and which allow further manipulation of the model in order to make predictions (NCTM, 2000). There is, however, little awareness of how those models correspond to the real world situations they model, and what the implications of those relationships are. A mathematical description always involves simplification and the making of assumptions on the part of the creator of the description (Shapiro, 2000). A mathematical description or model cannot, therefore, fully explain a nonmathematical situation or event without some account of the relationship between mathematics per se and scientific reality. Thus, a philosophical inquiry into the nature, uses, and inherent limitations of mathematical models, and into the implications of the use of such models in our social and practical lives, is necessary in everyday mathematical practice, lest we become captives and victims of those uses and limitations.

It is not enough to know how to use models-students also need to understand and know how these models shape and control our everyday lives. For example, the quantification of knowledge through different evaluation models, of which the SATs 
are prime examples, raises questions not only regarding unstated epistemological assumptions and values; it also leads us to critically examine the role of mathematics in social reproduction, in determining social practices, and in organizing everyday experience. Those determinations follow on the general social and material blueprint of mathematics as a system and method, and they prefigure not only the mode of access to those products of mathematization, but also the mode of studying, using, interpreting, and evaluating them; thus, mathematics also acquires prescriptive and symbolic power (Davis \& Hersh, 1986; Skovsmose, 1994). Unless these aspects of mathematics as we practice it are brought into the open and discussed, there is an obvious danger of our students turning into uncritical consumers of mathematics with little or no understanding of the worldview it reinforces, and with no critical competence to judge mathematical productions and prescriptions.

Many proponents of critical mathematics education (e.g., D'Ambrosio, 2006; Skovsmose,1994; Bishop 1988, Keitel, Kotzmann \& Skovsmose, 1993; Vithal, 2007) understand the development of critical competence as one of the essential problems of democracy, which, in their opinion, should match mathematical and technological development. If participation in a democratic society is not restricted to following formal procedures of elections and government, but is understood as participating in direct democracy or, in Deweyan terms, as "a mode of associated living," then citizens should be able to critically appraise and scrutinize not only the math instrumentarium, and its results, but also the implications of its use. The urgency of the need for the inclusion of critical inquiry into the ethical, social, and political aspects of the uses of the discipline in math education programs is particularly salient now, in a global economy dominated by finance, since it has been recognized that the global collapse of 2008 was caused by the uncritical and unethical exploitation of mathematical financial models (Shrivastava \& Statler, 2011). Inquiry into the ethical questions that pervade an increasingly mathematized world not only promises to raise awareness of the dangers of deceptively "value-free" instrumentalism, but also to open dialogue about the moral responsibility of the creators and the users of mathematical products.

Yet another inquiry that may have far-reaching implications for the development of the critical mathematical subject, and the prospects for the emergence of a truly autonomous citizenry, is epistemological. "Personal epistemology," a term now commonly used to denote personal beliefs about knowledge and knowing (Kuhn, Cheney, \& Weinstock, 2000), is increasingly recognized as a powerful hidden shaper of student expectations and learning practices, and thus as crucial for individual learning and development. In Dewey's terms, beliefs are habits that inform future action, but they are also susceptible to change through experience. For math learners, implicit and often unconscious beliefs about self in its relation to mathematics - about knowing, learning, and doing mathematics, about the social context of learning and doing mathematics, about the accessibility or inaccessibility of mathematics as a discipline, about its inherent value, usefulness or intrinsic inter- 
est-all of which make a crucial difference for success or failure in the classroom. Experiences that challenge negative beliefs and habits and render them inadequate promise to be transformational. A form of epistemological inquiry that prompts students to reflect and deliberate together on questions like "Can I become a better thinker? If so how?" "Can one be a good mathematician without knowing it?" "How do I know that I know or don't know mathematics?" "How does one get to know mathematics?" "What does it mean to know mathematics?" "What is mathematical understanding?" "What kind of a math learner am I?"-such an inquiry may represent a form of educative experience that challenges tacit assumptions and inherited beliefs about the nature of knowing, understanding, and learning, and is, as such, a powerful tool for the reconstruction of belief.

\section{Conclusion}

In this article I have outlined several potential avenues for philosophical inquiry in the practice of classroom mathematics: concept work; philosophical inquiry into the common, central, and contestable concepts that are common to the various disciplines; aesthetic inquiry in mathematics; inquiry into the benefits and the limitations of the mathematical instrumentarium; ethical inquiry into the uses of mathematics and in economy and society; and epistemological inquiry aimed at the reconstruction of mental beliefs and habits. Community of philosophical inquiry, with its dialectical process of knowledge construction, invites children to pose questions of their own about mathematics, both in its internal relations and its relation to the world-and by implication encourages students to enter into dialogue with its epistemological assumptions and thereby take steps towards demythologizing mathematics and reconstructing critical core beliefs. Such communal experiences of philosophical inquiry, and their ongoing reintegration with standard mathematical practice, promise to afford a larger space of inquiry for the student-one that is both more holistic and differentiated, more connected with experience, with knowledge, and with other disciplines. To introduce group philosophical practice into the everyday world of the mathematics classroom represents a step towards the realization of Dewey's vision of optimal educative experience as a process of continuous and cumulative interactions that build bridges between the child and the collective, the child and the curriculum, and the child and the cultural and social world.

\section{References}

Bishop, A. (1988). Mathematical enculturation: A cultural perspective on mathematics education. Dordrecht: Kluwer.

Boaler, J. \& Humphreys, C. (2005). Connecting mathematical ideas. Portsmouth, NH: Heinemann.

Boaler, J. (2002). Experiencing school mathematics. Mahwah, NJ: Lawrence Erlbaum. 
Cobb, P., Boufi, A., McClain, K., \& Whitenack, J. (1997). Reflective discourse and collective reflection. Journal for Research in Mathematics Education, 28(3), 258-277.

Cobb, P., Wood, T., \& Yackel, E. (1991). Analogies from the philosophy and sociology of science for understanding classroom life. Science Education, 75(1), 23- 44.

D’Ambrosio, U. (2006). Ethnomathematics. Rotterdam: Sense Publications.

Davis, P., \& Hersh, R. (1986). Descartes' dream: The world according to mathematics. Mineola, NY: Dover Publications.

Davydov, V. (1990). Types of generalization in instruction: Logical and psychological problems in the structuring of school curricula. Reston, VA: NCTM.

Deleuze, G. \& Guattari, F. (1994). What is philosophy? New York: Columbia University Press.

Dewey, J. (1934.) Art as experience. New York: Capricorn Books.

Dewey, J. (1933). How we think. Lexington, MA: D.C. Hearth.

Dewey, J. (1916). Democracy and education. New York: Free Press.

Goos, M. (2004). Learning mathematics in a classroom community of inquiry. Journal for Research in Mathematics Education, 35(4), 258-291.

Hersh, R., \& John-Steiner, V. (2011). Loving and hating mathematics. Princeton, NJ: Princeton University Press.

House, D. (2006). Mathematics beliefs and achievement of elementary school students in Japan and the United States: Results from the Third International Mathematics and Science Study. The Journal of Genetic Psychology, 167(1), 31-45.

Keithel, C., Kotzmann, E., \& Skovsmose, O. (1993). Beyond the tunnel vision: Analysing the relationship between mathematics, society, and technology. In C. Keithel \& K. Ruthven (Eds.), Learning from computers: Mathematics education and technology, (pp. 243-279). Berlin: Springer.

Kennedy, N. S. (2012a). Interrogation as interruption in the mathematics classroom. In M. Santi \& S. Oliverio (Eds.), Educating for complex thinking through philosophical inquiry: Models, advances, and proposals for the new millennium (pp. 257-270). Napoli: Liguori.

Kennedy, N. S. (2012b). Conceptual development through dialogue: A Vygotskian account. In L. Cho-Sik \& J. Park ( Eds.), Thinking education through philosophy (pp. 58-73). Seoul, Korea: KATPIS.

Kennedy, N. S. \& Kennedy, D. (2011). Community of philosophical inquiry as a discursive structure, and its role in school curriculum design. Journal of Philosophy of Education, 45(2), 265-283.

Kuhn, D. , Cheney, R., \& Weinstock, M. (2000). The development of epistemological understanding. Cognitive Development, 15, 309-328.

Lakoff, G. \& Nunez, R. (2000). Where mathematics comes from. New York: Basic Books.

Lampert, M. (1990). When the problem is not the question and the solution is not the answer: Mathematical knowing and teaching. American Educational Research Journal, 27, 29-63. 
Lipman, M. (1996). Natasha: Vygotskyan dialogues. New York: Teachers College Press.

Lipman, M. (2003). Thinking in education. (2nd. ed.). New York: Cambridge University Press.

Lipman, M, Sharp, A. \& Oscanyan, F. (1980). Philosophy in the classroom (2nd. ed.). Philadelphia, PA: Temple University Press.

Mead, G. H. (1934). Mind, self, and society. Chicago: University of Chicago Press. Middleton, J. \& Spanias, P. (1999) Motivation for achievement in mathematics: Findings, generalizations, and criticisms of the research. Journal for Research in Mathematics Education, 30(1), 65-88.

NCTM. (2000). Principles and standards for school mathematics. Reston, VA: NCTM. Peirce, C.S. (1931/1932). The collected papers. Vol. 1-6. Ed. C. Hartshorne \& P. Weiss. Cambridge, MA: Harvard University Press.

Royce, J. (1968). The problem of Christianity. Ed. John Smith. Chicago: University of Chicago Press.

Schoenfeld, A. H. (1989) What's all the fuss about metacognition? In A. H. Schoenfeld (Ed.), Cognitive science and mathematics education (pp. 189-215). Hillsdale, NJ: Erlbaum.

Shapiro, S. (2000). Thinking about mathematics: The philosophy of mathematics. Oxford: Oxford University Press.

Shrivastava, P. \& Statler, M. (2011). Learning from the global financial crisis. Stanford, CA: Stanford Business Books.

Skovsmose, O. (1994). Towards a philosophy of critical mathematics education. Dordrecht: Kluwer.

Tobias, S. (1993). Overcoming math anxiety. New York: Norton.

Vithal, R. (2006). The "uncivilized" scientist. In U. Gellert, E. Jablonka (Eds.), Mathematisation and demathematisation, (pp. 95-105). Rotterdam: Sense Publications.

Vygotsky, L. (1978). Mind in society: The development of higher psychological processes. Ed. M. Cole, V. John-Steiner, S. Scribner, \& E. Souberman. Cambridge, MA: Harvard University Press.

Wells, G. (1999). Dialogic inquiry: Towards a sociocultural practice and theory of education. Cambridge: Cambridge University Press.

Nadia Stoyanova Kennedy is Assistant Professor of Mathematics at SUNY Stony Brook.

E-mail:nadia@math.sunysb.edu 